\title{
125| Radioactive Seeds Implantation Therapy for Hepatocellular Carcinoma
}

\author{
Jin $\mathrm{Lv}^{\mathrm{a}}$, Xiu Feng Cao ${ }^{\mathrm{a}, \mathrm{b}}$, Bin $\mathrm{Zhu}^{\mathrm{a}}$
}

\begin{abstract}
Background: This study was to evaluate the outcome and the prognostic factors of unresectable hepatocellular carcinoma (HCC) patients with ${ }^{125} \mathrm{I}$ radioactive seeds implantation, who had failed transcatheter arterial chemoembolization (TACE).
\end{abstract}

Methods: From September 2002 to March 2006, 48 patients with unresectable HCC underwent ${ }^{125} \mathrm{I}$ permanent implantation brachytherapy. Thirty-eight patients were male and 10 were female. Mean age was 59 years, ranginging from 32 to 86 . Karnofsky performance status (KPS) was 100 in 10 patients, 80 in 21 patients, and 60 in 17 patients. According to Child-Pugh classification of liver, 34 patients were in class A and 14 patients in class B. Twenty-two patients had alpha-fetoprotein (AFP) level $>400 \mathrm{ng} / \mathrm{ml}$. Tumor size was $<5 \mathrm{~cm}$ in 17 patients, $5-10 \mathrm{~cm}$ in 18 patients, and $>10 \mathrm{~cm}$ in 13 patients. Thirty-four patients had confluent tumors, 14 patients presented single hepatic tumor. Serum hepatitis antigen markers were positive for type $\mathrm{B}$ in 38 patients and type $\mathrm{C}$ in 10 patients. Twentytwo patients had Okuda Stage I, 24 patients Stage II, and 2 patients Stage III. According to the AJCC staging system (6th edition), 10 patients were in Stage II (T2N0M0), 20 in Stage IIIa (T3N0M0) and 18 in Stage IIIb (T4N0M0).

Results: An objective response was observed in 34 of 48 patients, giving a response rate of $70.8 \%$. The survival rates at 1,2 and 3 years were $75 \%, 45.8 \%$ and $27.1 \%$, respectively. In the analysis of prognostic factors, tumor type, tumor size, Okuda stage, AJCC stage, Liver Child-Pugh, pretreatment AFP level, and matched peripheral dose (MPD) all had significant impact on survival.

Manuscript accepted for publication April 24, 2009.

ancology Center, Department of Surgery, Nanjing First Hospital Affiliated to Nanjing Medical University, Nanjing 210006, Jiangsu Province, China

bCorresponding author: cxf551101@sina.com

doi:10.4021/gr2009.05.1289
Conclusions: The ${ }^{125}$ I permanent implantation brachytherapy induced a substantial tumor response rate of $70.8 \%$ with survival rates at 1,2 and 3 years of $75 \%, 45.8 \%$ and $27.1 \%$, respectively, and a median survival time of 15.5 months in patients with unresectable HCC who had failed TACE. The complications are acceptable and can be managed with conservative treatment. Although we do not know whether there is a survival benefit through the use of this treatment, ${ }^{125}$ I permanent implantation brachytherapy seems to be a practical method of salvage for this subset of patients. Further study is warranted to evaluate the survival of such patients with controlled trial.

Keywords: ${ }^{125}$ I; Brachytherapy; Hepatocellular carcinoma; Transcatheter arterial chemoembolization

\section{Introduction}

Hepatocellular carcinoma (HCC) is one of the most common malignancies and the third most common cause of cancer death worldwide, with an overall five-year survival rate of approximately $5 \%$ [1]. Surgical resection and transplantation have been considered the optimal therapies for long-term control of the disease. However, most patients with HCC present with advanced disease, only $10 \%$ to $20 \%$ of patients suitable for surgical intervention due to multiple tumors, inadequate liver function, and/or involvement of vascular or major biliary structures. In many trials, transcatheter arterial chemoembolization (TACE) had been shown to improve survival compared to best supportive care in patients with unresectable HCC $[2,3]$. However, its benefit is modest and limited. Therefore, it should be considered for combination with other adjuvant treatment. In recent 20 years, $\mathrm{HCC}$ belonging to the radiosensitive tumor had been confirmed. With the development of the new radiotherapy technology and facility, the research about brachyhtherapy, especially ${ }^{125} \mathrm{I}$ seeds implantation therapy, has provoked more interests in the world. The purpose of this study was to evaluate the outcome and the prognostic factors of unresectable HCC patients, who failed the TACE, treated with ${ }^{125} \mathrm{I}$ radioactive seeds implantation therapy. 


\section{Materials and Methods}

\section{Patients}

All patients signed the informed consent prior to their inclusion in the study, which had been reviewed by the appropriate ethics committee and had been performed in accordance with the ethical standards laid down in an appropriate version of the 1964 Declaration of Helsinki. From September 2002 to March 2006, 58 patients with unresectable HCC were referred, in Oncology Center Surgery of Nanjing First Hospital, for ${ }^{125} \mathrm{I}$ seeds implantation. These patients had failed TACE. No patient had received prior radiotherapy for liver disease. Ten patients were excluded owing to ChildPugh class $\mathrm{C}$ or Karnofsky performance status (KPS) $<50$. The diagnosis of HCC was based on histological confirmation or on radiography (by CT scan as well as hepatic angiography) and a serum alpha-fetoprotein (AFP) value $>400$ $\mathrm{ng} / \mathrm{ml}$. Those patients with AFP level $<400 \mathrm{ng} / \mathrm{ml}$ underwent liver biopsy for diagnosis. The judgment of TACE failure was based on tumor progression demonstrated on computerized tomography (CT) scan after several sessions. The frequency of TACE was 2-6 sessions (median 4) and time interval between the last TACE and the start of intrahepatic ${ }^{125}$ I brachytherapy was 4 weeks. Patients' characteristics are shown in Table 1. Thirty-eight patients were male and 10 female. Mean age was 59 years, ranging from 32 to 86 . KPS was 100 in 10 patients, 80 in 21 patients, and 60 in 17 patients. According to Child-Pugh classification for cirrhosis of the liver, 34 patients were in class A and 14 patients in class B. Twenty-two patients had AFP level $>400 \mathrm{ng} / \mathrm{ml}$. Tumor size was defined as the mean of three diameters on CT scan, $<5 \mathrm{~cm}$ in 17 patients, $5-10 \mathrm{~cm}$ in 18 patients, and $>10 \mathrm{~cm}$ in 13 patients. Thirty-four patients had massive tumors, 14 patients presented single hepatic tumor. The percentage of positive $\mathrm{HBV} / \mathrm{HCV}$ patient was $79.2 \%$ and $20.8 \%$, respectively. Twenty-two patients had Okuda Stage I, 24 patients Stage II, and 2 patients Stage III. According to the AJCC staging system (6th edition), 10 patients were in Stage II (T2N0M0), 20 in Stage IIIa (T3N0M0) and 18 in Stage IIIb (T4N0M0).

\section{Implantation brachytherapy planning}

A treatment-planning CT scan was performed that included a portion of the inferior chest and the entire abdomen to allow for planning of non-axial fields. The gross tumor volume (GTV) was defined as high CT value area in early phase contrast-enhanced CT images. The clinical target volume (CTV) was defined as the GTV plus $1 \mathrm{~cm}$. The planning target volume (PTV) was defined as the CTV plus 0.5 $\mathrm{cm}$ for daily patient setup variation, and $1 \mathrm{~cm}$ in the cranialcaudal dimension to account for the ventilatory motion of the liver. Treatment plans were designed for each patient with the high-dose region including the PTV. The postplans were evaluated with both dose-volume histogram (DVH) and the matched peripheral dose (MPD). Table 2 shows the char-
Table 1. Patient characteristics $(n=48)$

\begin{tabular}{|c|c|}
\hline Characteristic & Number of patients(\%) \\
\hline Age (mean) & $32-86$ years $(59)$ \\
\hline \multicolumn{2}{|l|}{ Gender } \\
\hline Male (\%) & $38(79.2 \%)$ \\
\hline Female (\%) & $10(20.8 \%)$ \\
\hline \multicolumn{2}{|l|}{ KPS } \\
\hline 100 & $10(20.8 \%)$ \\
\hline 80 & $10(20.8 \%)$ \\
\hline 60 & $17(35.4 \%)$ \\
\hline \multicolumn{2}{|l|}{ Viral antigen } \\
\hline HBV & $38(79.2 \%)$ \\
\hline $\mathrm{HCV}$ & $10(20.8 \%)$ \\
\hline \multicolumn{2}{|l|}{ AFP (ng/ml) } \\
\hline$>400$ & $22(45.8 \%)$ \\
\hline$\leq 400$ & $26(54.2 \%)$ \\
\hline \multicolumn{2}{|l|}{ Tumor Size } \\
\hline$<5 \mathrm{~cm}$ & $17(35.4 \%)$ \\
\hline $5-10 \mathrm{~cm}$ & $23(47.9 \%)$ \\
\hline$>10 \mathrm{~cm}$ & $8(16.7 \%)$ \\
\hline \multicolumn{2}{|l|}{ Tumor type } \\
\hline Single & $14(29.2 \%)$ \\
\hline Massive & $34(70.8 \%)$ \\
\hline \multicolumn{2}{|l|}{ Liver Child-Pugh } \\
\hline A & $34(70.8 \%)$ \\
\hline $\mathrm{B}$ & $14(29.2 \%)$ \\
\hline \multicolumn{2}{|l|}{ Okuda stage } \\
\hline I & $22(45.8 \%)$ \\
\hline II & $24(50 \%)$ \\
\hline III & $2(4.2 \%)$ \\
\hline \multicolumn{2}{|l|}{ AJCC stage } \\
\hline II & $10(20.8 \%)$ \\
\hline IIIa & $20(41.7 \%)$ \\
\hline IIIb & $18(37.5 \%)$ \\
\hline \multicolumn{2}{|l|}{ Prior TACE (\%) } \\
\hline 2 & $5(10.4 \%)$ \\
\hline $2+$ & $43(89.6 \%)$ \\
\hline TACE median sessions & $4(95 \%$ CI, $4-5)$ \\
\hline
\end{tabular}

acteristics of ${ }^{125}$ I brachytherapy. Patients were placed in a supine position with both arms raised above the head and with the head in a natural position. In order to suppress the movement of respiration, patients were immobilized using a low-density body cradle and the breathing of the patient was repressed by applying thermoplastic material on the abdomen. After target-volume determination, interstitial needles (18-gauge, stainless steel, hollow needles, $15 \mathrm{~cm}$ long) were 
Table 2. characteristics of 125 I brachytherapy

\begin{tabular}{cl}
\hline Characteristic & Number of patients (\%) \\
\hline Activity per seed & \\
$0.4 \mathrm{mCi}$ & $10(20.8 \%)$ \\
$0.7 \mathrm{mCi}$ & $23(47.9 \%)$ \\
$1.0 \mathrm{mCi}$ & $15(31.3 \%)$ \\
Number of seeds & \\
$30-40$ & $8(16.7 \%)$ \\
$41-60$ & $21(43.8 \%)$ \\
$\geq 61$ & $18(37.5 \%)$ \\
Total activity & $10(20.8 \%)$ \\
$10-20 \mathrm{mCi}$ & $30(62.5 \%)$ \\
$21-30 \mathrm{mCi}$ & $8(16.7 \%)$ \\
$31-50 \mathrm{mCi}$ & \\
MPD & $12(25 \%)$ \\
$60-80 \mathrm{~Gy}$ & $29(60.4 \%)$ \\
$90-120 \mathrm{~Gy}$ & $7(14.6 \%)$ \\
$130-160 \mathrm{~Gy}$ & \\
Number of implant sites & $40(83.3 \%)$ \\
1 & $5(10.4 \%)$ \\
2 & $3(6.25 \%)$ \\
3 & \\
\hline
\end{tabular}

mCi: millicuries; MPD: matched peripheral dose; Gy: gray.

inserted into the tumor, approximately $1 \mathrm{~cm}$ apart. CT was used to guide the placement of the needles. Precautions were taken to avoid puncture of large blood vessels (central vein and inferior vena cava). Any bleeding was stopped by application of pressure. A Mick applicator (Radioactive seeds Implantation Instruments, HTA CO., LTD., China) was then sequentially attached to the distal end of each needle to place the ${ }^{125}$ I seeds (Model-6711, HTA CO., LTD., China) into the tumor, spaced approximately $1 \mathrm{~cm}$ apart along the needle track. A median of 60 seeds (range, 30-108) was implanted per patient, with a median activity per seed of $0.7 \mathrm{mCi}$ and

Table 3. Response of unresectable hepatic tumor to 125 I brachytherapy

\begin{tabular}{ll}
\hline Response & Number of patients (\%) \\
\hline CR & $8(16.7 \%)$ \\
PR & $26(54.2 \%)$ \\
SD & $10(20.8 \%)$ \\
PD & $4(8.3 \%)$ \\
\hline
\end{tabular}

CR: complete response; PR: partial response; SD: stable disease; PD: progressive disease.
Table 4. Acute toxicity of 125 l brachytherapy $(n=48)$

\begin{tabular}{lllll}
\hline & \multicolumn{5}{c}{ Toxicity grade } & \\
& $\mathbf{1}$ & $\mathbf{2}$ & $\mathbf{3}$ & $\mathbf{4}$ \\
\hline & 2 & 3 & - & - \\
Transaminase & 1 & 2 & - & - \\
Bilirubin & 2 & 3 & - & - \\
Albumin & 2 & 2 & - & - \\
Alkaline phosphatase & 2 & 3 & - & - \\
Leucopenia & 3 & 2 & - & - \\
Anemia & 5 & 3 & - & - \\
Thrombocytopenia & 1 & 3 & & \\
\hline
\end{tabular}

a median total implanted activity of $22.6 \mathrm{mCi}$ (range, 10$70 \mathrm{mCi}$ ). The $83.3 \%$ percent of the patients had only 1 site implanted, whereas $16.7 \%$ had 2 or 3 sites implanted. The median MPD was 114Gy (range, 60-160Gy). For most implants, more than $50 \%$ of the target volume received between 90 and 120 Gy.

During the treatment, the patients were monitored weekly with physical examination and blood chemistry evaluation. Evaluation of tumor response was based on serial CT scans. All patients had CT scans before initiation of brachytherapy and 4 weeks after completion of radiation therapy and then at 1-3 months intervals. Complete disappearance of hepatic tumor was considered as complete response (CR); decrease of less than $50 \%$ of the tumor size as partial response (PR); decrease of more than $50 \%$ of the tumor size or no change as stable of disease (SD); and progression as progressive disease (PD). Acute toxicity was evaluated weekly during the treatment and 1 month following the treatment

Table 5. Actuarial overall survival $(n=48)$

\begin{tabular}{ll}
\hline Category & Number of Patients \\
\hline Number remaining alive & $9(18.8 \%)$ \\
Death of intrahepatic disease & $16(33.3 \%)$ \\
Death of extrahepatic disease & $7(14.6 \%)$ \\
Death of complications of & \\
$\quad$ further Treatment & $10(20.8 \%)$ \\
Death of unrelated cause & $6(12.5 \%)$ \\
Actuarial survival & \\
1 year & $75 \%$ \\
2 year & $45.8 \%$ \\
3 year & $27.1 \%$ \\
Median survival time & $15.5 \mathrm{months}$ \\
& $(95 \% \mathrm{CI}, 12.7-27)$ \\
\hline
\end{tabular}


Table 6. Actuarial overall survival $(n=48)$

\begin{tabular}{|c|c|c|c|c|c|}
\hline \multirow[t]{2}{*}{ Patient group } & \multicolumn{2}{|c|}{ Survival rate (\%) } & \multirow[b]{2}{*}{$3-Y$} & \multirow{2}{*}{$\begin{array}{l}\text { Mean survival } \\
\text { (months) }\end{array}$} & \multirow[t]{2}{*}{$\mathbf{P}$} \\
\hline & $1-Y$ & $2-Y$ & & & \\
\hline All patients & $75 \%$ & $45.8 \%$ & $27.1 \%$ & $24.2(95 \%$ CI, 19.2-29.2) & - \\
\hline \multicolumn{6}{|l|}{ Age (years) } \\
\hline$<50$ & $80 \%$ & $60 \%$ & $40 \%$ & $28.9(95 \%$ CI, 14.7-43.1) & 0.4683 \\
\hline$\geq 50$ & $73.7 \%$ & $42.1 \%$ & $23.7 \%$ & $22.9(95 \%$ CI, 17.5-28.4) & \\
\hline \multicolumn{6}{|l|}{ Gender } \\
\hline Male & $76.3 \%$ & $44.7 \%$ & $26.3 \%$ & $22.9(95 \%$ CI, 17.7-28.1) & 0.5499 \\
\hline Female & $70 \%$ & $50 \%$ & $30 \%$ & $29.1(95 \%$ CI, 13.1-45.1) & \\
\hline KPS & & & & & 0.3461 \\
\hline 100 & $80 \%$ & $60 \%$ & $40 \%$ & $28.9(95 \% \mathrm{CI}, 14.7-43.1)$ & - \\
\hline 80 & $81 \%$ & $57.1 \%$ & $28.6 \%$ & 26.5 (95\% CI, 18.4-34.6) & - \\
\hline 60 & $64.7 \%$ & $23.5 \%$ & $17.6 \%$ & $18.5(95 \%$ CI, 11.2-25.8) & - \\
\hline \multicolumn{6}{|l|}{ Tumor type } \\
\hline Single & $92.9 \%$ & $71.4 \%$ & $64.3 \%$ & $41.2(95 \%$ CI, 29.8-52.6) & 0.0001 \\
\hline Massive & $67.6 \%$ & $32.4 \%$ & $11.8 \%$ & $17.1(95 \% \mathrm{CI}, 13.7-20.6)$ & \\
\hline Tumor Size & & & & & 0.0000 \\
\hline$<5 \mathrm{~cm}$ & $94.1 \%$ & $70.6 \%$ & $52.9 \%$ & $35.5(95 \%$ CI, 25.6-45.5) & \\
\hline $5-10 \mathrm{~cm}$ & $82.6 \%$ & $43.5 \%$ & $17.4 \%$ & $21.1(95 \%$ CI, 15.6-26.7) & \\
\hline$>10 \mathrm{~cm}$ & $12.5 \%$ & $0 \%$ & $0 \%$ & 8.75 (95\% CI,6.9-10.6) & \\
\hline \multicolumn{6}{|l|}{ Okuda stage } \\
\hline $\mathrm{I}$ & $95.4 \%$ & $72.7 \%$ & $45.5 \%$ & 33 (95\% CI, 25.3-40.7) & 0.0011 \\
\hline II+III & $57.7 \%$ & $23.1 \%$ & $11.5 \%$ & 16.7 (95\% CI, 11.3-22.1) & \\
\hline \multicolumn{6}{|l|}{ AJCC stage } \\
\hline II & $90 \%$ & $80 \%$ & $70 \%$ & 41.7 (95\% CI, 28-55.4) & 0.0011 \\
\hline $\mathrm{IIIa}+\mathrm{IIIb}$ & $71.1 \%$ & $36.8 \%$ & $15.8 \%$ & $19.6(95 \% \mathrm{CI}, 15.1-24)$ & \\
\hline \multicolumn{6}{|c|}{ Liver Child-Pugh } \\
\hline A & $85.3 \%$ & $61.8 \%$ & $35.3 \%$ & 29.5 (95\% CI, 23.4-35.5) & 0.0000 \\
\hline $\mathrm{B}$ & $35.7 \%$ & $7.1 \%$ & $7.1 \%$ & 11.3 (95\% CI, 6.6-16) & \\
\hline \multicolumn{6}{|l|}{$\mathrm{AFP}(\mathrm{ng} / \mathrm{ml})$} \\
\hline$>400$ & $59.1 \%$ & $22.7 \%$ & $9.1 \%$ & $16.6(95 \% \mathrm{CI}, 11.1-22.1)$ & 0.0013 \\
\hline$\leq 400$ & $88.5 \%$ & $65.4 \%$ & $42.3 \%$ & 30.6 (95\% CI, 23.2-38) & \\
\hline MPD & & & & & 0.0223 \\
\hline $60-80$ Gy & $66.7 \%$ & $16.7 \%$ & $8.3 \%$ & 15.1 (95\% CI, 9.2-21) & \\
\hline 90-120 Gy & $86.2 \%$ & $58.6 \%$ & $34.5 \%$ & 29.1 (95\% CI, 22.3-36) & \\
\hline 130-160 Gy & $42.9 \%$ & $28.6 \%$ & $28.6 \%$ & $20.6(95 \%$ CI, 2-39.1) & \\
\hline
\end{tabular}

using the Radiation Therapy Oncology Group/European Organization for Research and Treatment of Cancer (RTOGEORTC) scale. Sub-acute or chronic toxicity was defined as occurring after 1 month. Survival was estimated from the date of diagnosis according to the Kaplan-Meier method. Log rank test was used in the analysis of prognostic factors.

\section{Results}

All patients underwent evaluation of tumor response based on CT scan. Among 48 patients with unresectable hepatic tumors, 8 patients achieved CR and 26 patients achieved PR (Table 3). In total, an objective response was observed in 


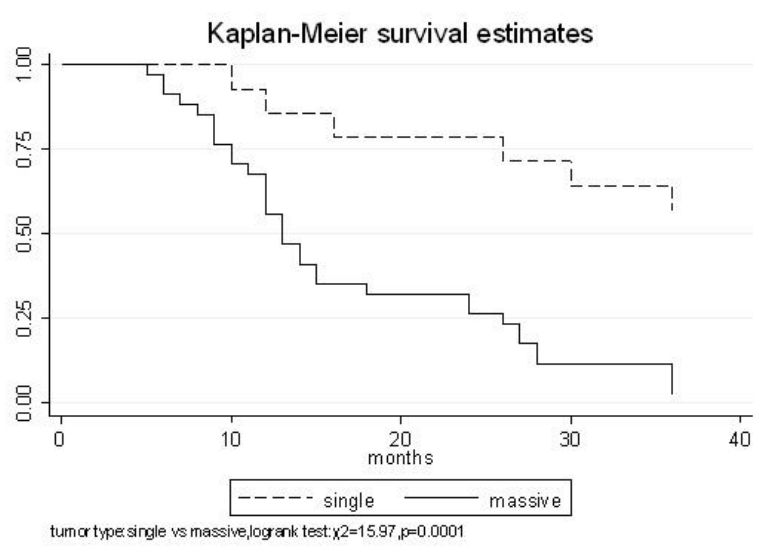

Figure 1. Tumor type, Single VS. Massive.

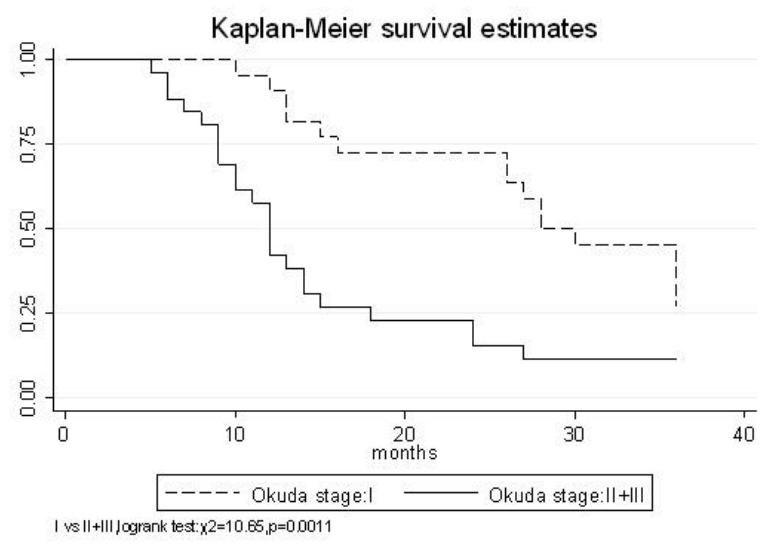

Figure 3. Okuda stage, I VS. II+III.

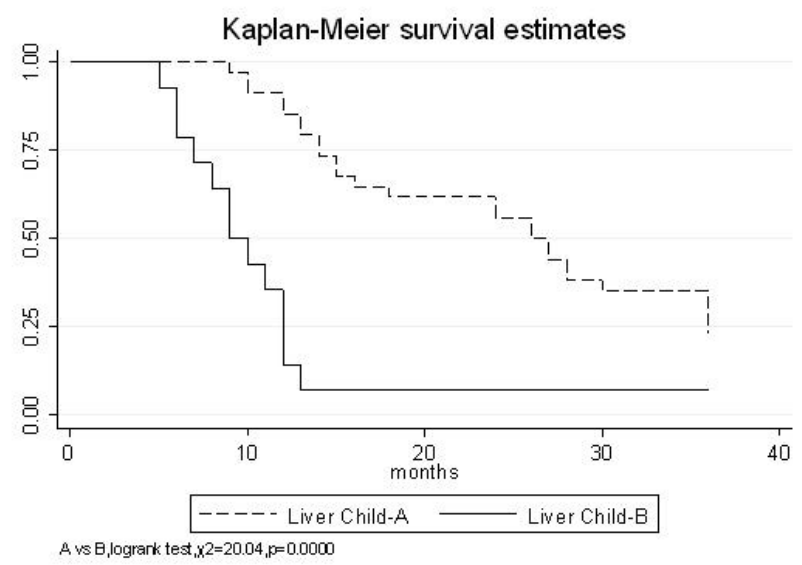

Figure 5. Liver Child-Pugh, A VS. B.

34 of 48 patients, giving a response rate of $70.8 \%$. At the time of last follow-up in March 2006, 9 patients remained alive and 39 were dead. 16 patients (33.3\%) developed intrahepatic metastasis outside the radiation field. Extrahepatic

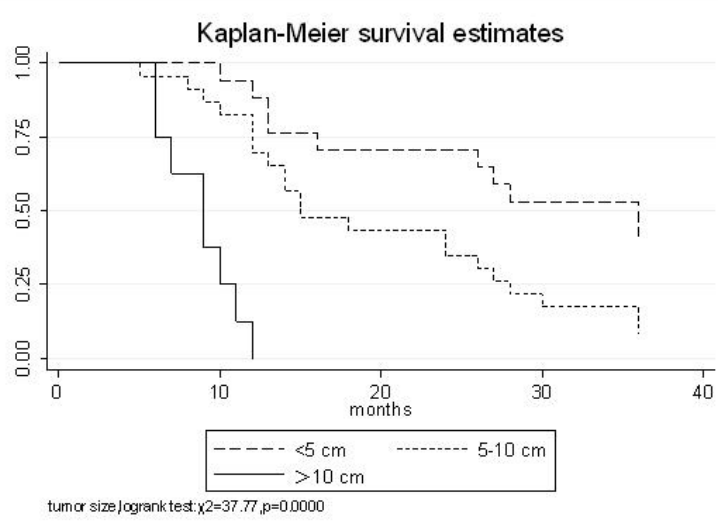

Figure 2. Tumor size, $<5 \mathrm{~cm}$ VS. $5-10 \mathrm{~cm} \mathrm{VS.}>10 \mathrm{~cm}$.

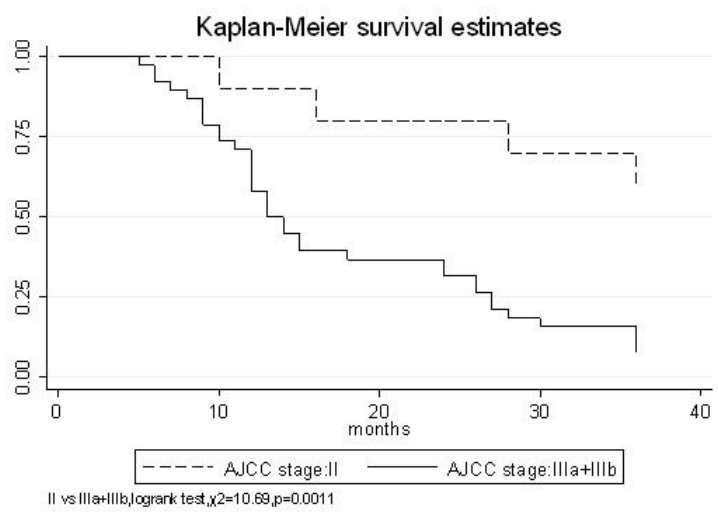

Figure 4. AJCC stage, II VS. IIla+IIlb.

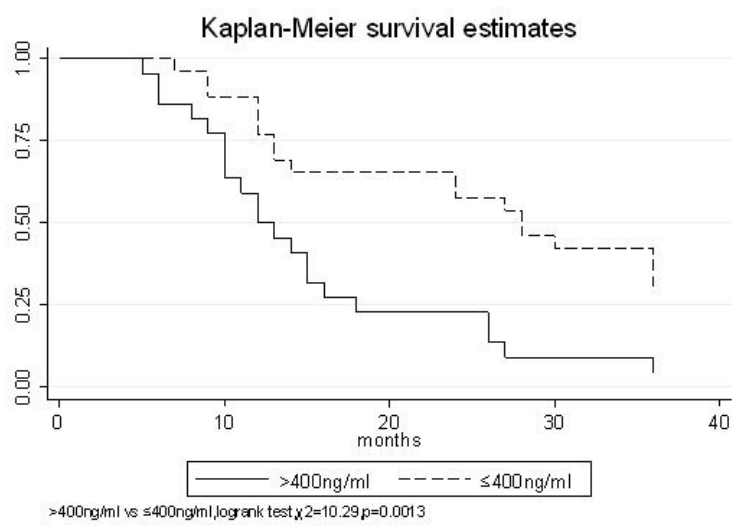

Figure 6. $\operatorname{AFP}(\mathrm{ng} / \mathrm{ml}),>400 \mathrm{VS} . \leq 400$.

metastasis developed in 7 patients $(14.6 \%)$, including 3 in lung and 4 in bone. There were no treatment-related deaths. Survival rates were evaluated in all patients from the time of diagnosis. Acute toxicity of ${ }^{125} \mathrm{I}$ brachytherapy is sum- 
marized in Table 4. The survival rates at 1, 2 and 3 years were $75 \%, 45.8 \%$ and $27.1 \%$, respectively, with a median survival time of 15.5 months (Table 5). Elevation of transaminase was seen in 5 patients ( 2 patients of grade 1 and 3 of grade 2), bilirubin in 3 patients ( 1 of grade 1 and 2 of grade 2), albumin in 5 patients ( 2 of grade 1 and 3 of grade 2 ) and alkaline phosphatase in 4 patients ( 2 of grade 1 and 2 of grade 2). Hematologic toxicity included thrombocytopenia in 4 patients ( 1 of grade 1 and 3 of grade 2), anemia in 7 patients ( 5 of grade 1 and 2 of grade 2 ) and leucocytopenia in 6 patients ( 3 of grade 1 and 3 of grade 2). No patient had radiation-related gastrointestinal bleeding. In the analysis of prognostic factors (Table 6), age, gender, performance status (KPS) did not influence survival significantly $(\mathrm{P}>0.05)$. Tumor type had significant impact on survival rates for single and massive (logrank test, $\mathrm{P}=0.0001$, Fig. 1). Tumor size had significant impact on survival rates for $<5 \mathrm{~cm}$ versus $5-10 \mathrm{~cm}$ and versus $>10 \mathrm{~cm}$ (logrank test, $\mathrm{P}=0.0000$, Fig. 2). Okuda stage had significant impact on survival rates for Stage I and Stage II plus III patients (logrank test, $\mathrm{P}=$ 0.0011, Fig.3). AJCC stage had significant impact on survival rates for stage II and IIIa+IIIb (logrank test, $\mathrm{P}=0.0011$, Fig.4). Liver Child-Pugh had significant impact on survival rates for Child-A and Child-B (logrank test, $\mathrm{P}=0.0000$, Fig. 5). Pretreatment AFP levels had a similar impact on survival (logrank test, $\mathrm{P}=0.0013$, Fig. 6). MPD also had a significant impact on survival (logrank test, $P=0.0223$, Fig. 7), indicating MPD 90-120Gy had higher survival rates than which of MPD 60-80Gy and MPD 130-160Gy.

\section{Discussion}

${ }^{125}$ I brachytherapy for the treatment of prostate carcinoma has been confessed successful [4-7], however, the sample therapy for HCC is still in research stage. Because of the sensitivity of the normal liver limits the dose that can be deliv-

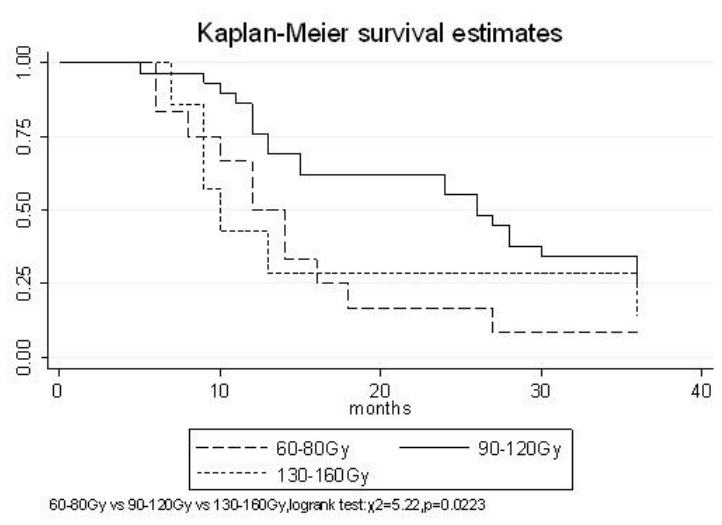

Figure 7. MPD, 60-80 Gy VS. 130-160 Gy VS.90-120 Gy. ered, radiotherapy has not been considered for the treatment of HCC for some time. However, ${ }^{125}$ I seeds brachytherapy is an ideal technique that combines the ability to target tumor cells under direct visualization and spare uninvolved liver parenchyma secondary to the sharp dose fall off outside of the implanted volume. Moreover, because of the liver's natural regenerative capabilities and its ability to tolerate loss of over $75 \%$ of its tissue without ensuing failure, high dose of radiation can be delivered to restricted volumes by brachytherapy. With the property of local "conformal radiotherapy", normal liver is spared, a potentially tumoricidal dose of radiation (much higher than whole-liver tolerance) can be administered with acceptable complications. TACE has been an effective therapeutic options for treatment of unresectable HCC [8], however, its benefit is limited. So, combination with other adjuvant treatment should be necessary. Our study of 48 patients is unique in that it is the largest series reported to date of ${ }^{125} \mathrm{I}$ brachytherapy in the successful treatment of advanced, unresectable HCC, who had failed with TACE, and has the longer follow-up.

The prognostic factors of $\mathrm{HCC}$ reported in the literature include tumor size, tumor type, tumor stage, serum AFP status, etc. In our study, tumor type, tumor size, Okuda stage, AJCC stage, liver Child-Pugh, AFP level, and MPD had significant impact on survival. Other known factors were not significant. The significance of the radiation dose has been suggested in terms of induction of tumor regression as well as in overall survival. The best prescription dosage of radioactive ${ }^{125}$ I seed interstitial implantation for HCC and the best radioactivity of seed are still controversial. Ricke J, et al [911] thought that the mean minimal dose inside the liver tumor margin amounted to $17-18 \mathrm{~Gy}$ (range, 10-25Gy); Zhang FJ, et al [12] described that ${ }^{125} \mathrm{I}$ seeds of the radioactivity of $30 \mathrm{MBq}, \mathrm{MPD}$ was 100 approximately $150 \mathrm{~Gy}$. These reports strongly support the importance of reasonable MPD in inducing tumor regression. In our study, the MPD had significant impact on survival. The survival rates of patients were higher, with MPD 90-120Gy, than which of less than 80Gy or more than $130 \mathrm{~Gy}(\chi 2=5.22, \mathrm{P}=0.0223)$. However, it should be mentioned that the function of the non-tumorous part of the liver might be compromised owing to preexisting parenchymal disease, especially cirrhosis of the liver. Most HCC patients referred for radiotherapy present with advanced unresectable disease, usually associated with cirrhosis of the liver. In the report of the University of Michigan group, 128 patients were treated with conformal hyperfractionated RT delivered with concurrent continuous infusion hepatic arterial FUdR. Thirty-eight patients (30\%) developed grade 3-4 toxicity, and 5 cases (4\%) of radiation-induced liver disease (RILD) were observed. The median survival of $35 \mathrm{HCC}$ patients was 15.2 months $[13,14]$. In our study, no sub-acute or chronic toxicity of grade 3-4 were observed and the median survival was 15.5 months. Nevertheless, the encouraging results did not mean that the occurrence of RILD could be 
ignored. In our group, the patients with Child-Pugh class $\mathrm{C}$ or KPS $<50$ were excluded. During the observation, there was neither treatment-related fatal hepatic toxicity nor radiation-related gastrointestinal complication, including gastroduodenal ulcer and bleeding, 34 patients obtained objective response with a response rate of $70.8 \%$. In reports of Zhang FJ et al [12], 37 of the 45 lesions obtained CR or PR, the response rate was $82.2 \%$, no other severe complications, such as massive hemorrhage, bile fistulae, and pancreatic fistula were seen. Using ${ }^{125} \mathrm{I}$ brachytherapy in our study, treatment plans according to TPS were designed for each patient, in which the high-dose region encompassed the planning target volume and spared normal tissues. Our study had no treatment-related deaths.

In conclusion, permanent ${ }^{125} \mathrm{I}$ brachytherapy induced a substantial tumor response rate of $70.8 \%$ with survival rates at 1,2 and 3 years of $75 \%, 45.8 \%$ and $27.1 \%$, respectively, and a median survival time of 15.5 months in patients with unresectable HCC who had failed TACE. Patients with massive tumor, tumor size $\geq 5 \mathrm{~cm}$, Okuda stage II/III, AJCC stage III, Liver Child-Pugh B, pretreatment AFP level of $>400 \mathrm{ng} /$ $\mathrm{ml}$, and MPD $\leq 80 \mathrm{~Gy}$ or $\geq 130 \mathrm{~Gy}$ had significantly shorter survival. With the property of local "conformal radiotherapy" and the advantages of minimal invasion, convenience, high performance, slight adverse effect, permanent ${ }^{125}$ I seeds implantation is a safe and effective adjuvant treatment for unresectable HCC. The complications are acceptable and can be managed with conservative treatment. Although we do not know whether there is a long-term survival benefit through the use of this treatment, permanent ${ }^{125} \mathrm{I}$ brachytherapy seems to be an important alternative to other locally ablative techniques for this subset of patients. Further study is warranted to evaluate the survival of such patients with controlled trials.

\section{Acknowledgements}

The authors declare no commercial associations or conflict of interests related to this article.

\section{References}

1. Parkin DM, Bray F, Ferlay J, Pisani P. Global cancer statistics, 2002[J]. CA Cancer J Clin, 2005; 55:74-108.

2. Llovet JM, Bruix J. Systematic review of randomized trials for unresectable hepatocellular carcinoma: Chemoembolization improves survival. Hepatology 2003;37:429-442.

3. Lo CM, Ngan H, Tso WK, Liu CL, Lam CM, Poon RT, Fan ST, et al. Randomized controlled trial of transarterial lipiodol chemoembolization for unresectable hepa- tocellular carcinoma. Hepatology 2002;35:1164-1171.

4. Hughes L, Waterman FM, Dicker AP. Salvage of suboptimal prostate seed implantation: Reimplantation of underdosed region of prostate base. Brachytherapy 2005;4:163-170.

5. Yorozu A, Toya K, Ohashi T, Ohsuga K, Ito R, Kasamatsu T, Saito S, et al. [Brachytherapy for prostate cancer]. Gan To Kagaku Ryoho 2006;33:424-427.

6. Machtens S, Baumann R, Hagemann J, Warszawski A, Meyer A, Karstens JH, Jonas U. Long-term results of interstitial brachytherapy (LDR-Brachytherapy) in the treatment of patients with prostate cancer. World J Urol 2006;24:289-295.

7. Frank SJ, Pisters LL, Davis J, Lee AK, Bassett R, Kuban DA. An assessment of quality of life following radical prostatectomy, high dose external beam radiation therapy and brachytherapy iodine implantation as monotherapies for localized prostate cancer. J Urol 2007; 177:21512156; discussion 2156.

8. Marelli L, Stigliano R, Triantos C, Senzolo M, Cholongitas E, Davies N, Tibballs J, et al. Transarterial therapy for hepatocellular carcinoma: which technique is more effective? A systematic review of cohort and randomized studies. Cardiovasc Intervent Radiol 2007;30:6-25.

9. Ricke J, Wust P, Stohlmann A, Beck A, Cho CH, Pech M, Wieners G, et al. [CT-Guided brachytherapy. A novel percutaneous technique for interstitial ablation of liver metastases]. Strahlenther Onkol 2004;180:274-280.

10. Ricke J, Wust P, Stohlmann A, Beck A, Cho CH, Pech M, Wieners G, et al. CT-guided interstitial brachytherapy of liver malignancies alone or in combination with thermal ablation: phase I-II results of a novel technique. Int J Radiat Oncol Biol Phys 2004;58:1496-1505.

11. Ricke J, Wust P, Wieners G, Beck A, Cho CH, Seidensticker M, Pech M, et al. Liver malignancies: CT-guided interstitial brachytherapy in patients with unfavorable lesions for thermal ablation. J Vasc Interv Radiol 2004; $15: 1279-1286$.

12. Zhang FJ, Li CX, Wu PH, Li K, Huang JH, Fan WJ, Zhang L, et al. [Radioactive seed ${ }^{125} \mathrm{I}$ implantation in treating recurrence and metastasis after liver transplantation in hepatoma]. Zhonghua Yi Xue Za Zhi 2007;87:956-959.

13. Ben-Josef E, Normolle D, Ensminger WD, Walker S, Tatro D, Ten Haken RK, Knol J, et al. Phase II trial of high-dose conformal radiation therapy with concurrent hepatic artery floxuridine for unresectable intrahepatic malignancies. J Clin Oncol 2005;23:8739-8747.

14. Dawson LA, McGinn CJ, Normolle D, Ten Haken RK, Walker S, Ensminger W, Lawrence TS. Escalated focal liver radiation and concurrent hepatic artery fluorodeoxyuridine for unresectable intrahepatic malignancies. J Clin Oncol 2000;18:2210-2218. 